EXPERIMENTAL STUDY

\title{
Increased insulin sensitivity and decreased body weight in female rats after postnatal corticosterone exposure
}

\author{
Cecilia Nilsson ${ }^{1,4}$, Eva Jennische ${ }^{2}$, Hoi-Por $\mathrm{Ho}^{3}$, Elias Eriksson ${ }^{3}$, Per Björntorp ${ }^{1,4}$ and Agneta Holmäng ${ }^{1,4}$ \\ ${ }^{1}$ Cardiovascular Institute, ${ }^{2}$ Department of Histology, ${ }^{3}$ Department of Pharmacology and ${ }^{4}$ Wallenberg Laboratory, Göteborg University, Sweden \\ (Correspondence should be addressed to Cecilia Nilsson, Wallenberg Laboratory, Göteborg University, S-413 45 Göteborg, Sweden; \\ Email: Cecilia.Nilsson@biovitrum.com)
}

\begin{abstract}
Objective: Glucocorticoids are important for normal brain development. Elevation or removal of these hormones can permanently modify the structure and function of the fetal brain. The purpose of this study was to examine the effects of postnatal corticosterone exposure of female pups on metabolic, endocrine and anthropometric variables in adulthood.

Design: Female pups were given subcutaneous injections of corticosterone $(5 \mathrm{mg} / \mathrm{kg}, \mathrm{CORT})$ or vehicle 3 and 5 days after birth.

Results: From 6 weeks of age, the CORT rats weighed significantly less than did controls, with diminished fat depots, decreased serum levels of leptin and reduced food intake. Adult CORT rats showed increased insulin sensitivity, measured by hyperinsulinemic, euglycemic clamp $(5 \mathrm{mU} / \mathrm{kg} / \mathrm{min})$, as compared with controls. CORT rats had lower basal corticosterone levels and lower corticosterone levels 15 and $90 \mathrm{~min}$ after exposure to stress.

Conclusion: The results indicate that postnatal exposure to corticosterone leads to increased insulin sensitivity, low body weight with diminished fat depots, leptin and food intake. This suggests that postnatal exposure to corticosterone induces specific programming, with consequences in adult life.
\end{abstract}

European Journal of Endocrinology 146 847-854

\section{Introduction}

Glucocorticoids play a series of key roles in physiology, maintaining fuel metabolism under basal conditions and underpinning many of the body's adjustments to stressful stimulation.

Synthetic glucocorticoids are today extensively used in neonatological practice to reduce complications associated with preterm delivery (1). Currently very little information is available of the long-term effects of excess neonatal glucocorticoids on brain and neuroendocrine development. Low, constant levels of glucocorticoids are crucial for normal development of the central nervous system. Excess glucocorticoids, however, disturb brain development and can permanently alter structure and function of the brain (2).

In rats, dexamethasone exposure in early pregnancy leads to offspring with changed hypothalamo-pituitaryadrenal (HPA) axis activity and concomitant obesity (3). Dexamethasone exposure in late gestation results in adult offspring with hypertension, hyperinsulinemia, increased basal corticosterone levels, and increased hepatic glucocorticoid receptor (GR) expression at adult age $(4,5)$.
Rats, rabbits and mice give birth to immature young where much neuroendocrine development occurs postnatally (6). This contrasts with primates, where the majority of neuroendocrine maturation takes place in utero (7). Exposure to excess glucocorticoids in rats during the first week of life leads to permanently reduced brain weights and DNA content $(8,9)$. Perinatal glucocorticoid exposure is followed by alterations in social behavior and performance in learning tests $(10,11)$. Early postnatal dexamethasone treatment results in adult rats with blunted HPA axis response to stress (12). Likewise, neonatal handling leads to adult animals exhibiting an attenuated HPA axis response to stress together with an increased density of GRs in the hippocampus and frontal cortex (13), whereas repeated maternal separation results in an increased HPA axis response to stress (14).

In a recent study, we observed that early postnatal endotoxin exposure leads to programming of insulin sensitivity and HPA axis regulation (15). Endotoxin is a powerful stimulator of glucocorticoid secretion, and corticosterone treatment in infant rats leads to impaired glucose homeostasis in the adult rat (16, 17). 
With this background, the aim of this study was to elucidate the long-term effects of postnatal administration of corticosterone, the endogenous glucocorticoid in rats. The focus of this study was to examine adult body composition, insulin sensitivity, neuroendocrine function and exploratory behavior after postnatal corticosterone exposure.

\section{Materials and methods}

\section{Animals}

Pregnant nulliparous Wistar rats were purchased from B\&K Universal (Sollentuna, Sweden) and were housed singly under controlled conditions (temperature $21-$ $22^{\circ} \mathrm{C}$, humidity $55-65 \%$, lights on from 0700 to $1900 \mathrm{~h})$ until parturition. Before the first injection, male pups were removed and female pups were randomly distributed among mothers so that each dam had approximately the same number of pups. Each nest contained only offspring given the same treatment. Pups were raised with a lactating mother until 4 weeks of age, and were then placed in cages housing two to four animals. All were fed with commercial rat chow containing $18.7 \%$ protein, $4.7 \%$ fat and $63 \%$ carbohydrates with sufficient supply of vitamins and minerals (B\&K Universal) and tap water was available ad libitum. The study was approved by the Animal Ethics Committee of Göteborg University.

\section{Study procedure}

Female pups received subcutaneous (s.c.) injections of $5 \mathrm{mg} / \mathrm{kg}$ corticosterone (CORT, Sigma Chemical Co., St Louis, MO, USA) dissolved in $0.1 \mathrm{ml}$ sesame oil on days 3 and 5 after birth. This dose is known to evoke a glucocorticoid response in the postnatal brain (18). Control pups were injected with sesame oil. Six hours after the first injection, five CORT and six control rats were decapitated and their blood collected for corticosterone analyses. The remaining pups were weaned at 4 weeks of age. Weight was measured once weekly from 4 weeks of age. Blood samples were taken after an overnight fast from a nick in the tail for determination of insulin, leptin (week 7) and, when the animals had reached sexual maturity, testosterone, $17 \beta$-estradiol and progesterone (week 9).

\section{Food intake}

Food consumption for each cage (three cages per group, three or four rats per cage) was recorded at 9 weeks of age. The rats were presented with the same amount of food and their intake was measured the following day by subtracting the uneaten food. This was done for 10 consecutive days and calculated as food intake in $\mathrm{g}$ per rat per day.

\section{Vaginal smear}

A vaginal smear was obtained daily for 10 consecutive days when the rats were 8-9 weeks old, to determine the estrous cycle (19). A cycle is divided into four stages: estrus, diestrus 1 , diestrus 2 , and proestrus. The usual duration of a cycle in rats is about 4 days. In this study, all rats exhibited normal cyclicity, with clear ovulation (measured as a characteristic, rich amount of epithelial cells without leukocytes in the smears). Blood samples for determination of sex hormones were taken the day after estrus.

\section{Locomotion}

Locomotor activity in a novel environment (i.e. exploratory behavior) was assessed in adult animals (20). Photocell animal motility meters in eight soundproof, ventilated boxes (Kungsbacka mät- och reglerteknik AB, Fjärås, Sweden) connected to a computer were used. The activity boxes with a floor area of $700 \mathrm{~mm} \times$ $700 \mathrm{~mm}$ were equipped with two rows of eight photocells each. Locomotor activity during 60 min was registered, in dim light, as the breaking of a sequence of beams, representing movement in a single direction. The time of day (between $1200 \mathrm{~h}$ and $1500 \mathrm{~h}$ ) was standardized for all groups. One rat from each group was excluded since, by the time of examination, they were in the proestrous phase of the cycle.

\section{Stress test procedure}

In 5-week-old rats, the corticosterone response to stress was tested. This was done by means of a so-called 'novel-environment stress' test, according to a modified protocol described by Lahti \& Barsuhn (21). All tests started at $0700 \mathrm{~h}$, and great care was taken to keep the rats undisturbed and fed the night before the experiment. Tail blood $(30 \mu \mathrm{l})$ was collected by a nick in the tail immediately before the test, for estimation of prestress levels of corticosterone. The rats were then transferred singly to a novel environment (new cages, laboratory room, loud background noise, bright light). Blood for corticosterone determination $(30 \mu \mathrm{l})$ was taken from the tail 15, 30, 60 and $90 \mathrm{~min}$ after exposure to the novel environment.

\section{Euglycemic hyperinsulinemic clamp (5 mU/kg/min)}

For estimation of insulin sensitivity, rats were subjected to a euglycemic hyperinsulinemic clamp as described previously (22). Animals were subjected to the euglycemic hyperinsulinemic clamp when they were 10 weeks old. The animals were anesthetized with $125 \mathrm{mg} / \mathrm{kg}$ body weight of thiobutabarbitural sodium (Inactin, RBI, Natick, MA, USA). Catheters were then inserted into the left carotid artery for blood sampling and 
into the right jugular vein for infusion of glucose and insulin. The body temperature was maintained at $37^{\circ} \mathrm{C}$ with a heating blanket. After a bolus injection, insulin (100 U/ml, Human Actrapid, Novo, Copenhagen, Denmark) was continuously infused at a rate of $5 \mathrm{mU} / \mathrm{kg} / \mathrm{min}$. A $10 \%$ glucose solution in physiological saline was administered to maintain the plasma glucose concentration at $7 \mathrm{mmol} / \mathrm{l}$. Glucose was infused at a speed guided by glucose concentration measurements in $30 \mu \mathrm{l}$ blood at regular intervals (every $5 \mathrm{~min}$ during the first $40 \mathrm{~min}$ and thereafter every $10 \mathrm{~min}$ ). At 0,40 , 80, 120, 160 and $200 \mathrm{~min}$ of infusion, $250 \mu \mathrm{l}$ blood samples were taken for determination of insulin concentration. A total of less than $2 \mathrm{ml}$ blood was used for the determinations, and compensated for by the infusion volumes. During the clamp, one control and one treated rat died.

\section{Tissues}

At the completion of the clamp, the rats were killed by intravenous injection of $\mathrm{KCl}$. The brain was quickly removed, and the hippocampus and hypothalamus dissected, snap-frozen in liquid nitrogen and stored at $-80^{\circ} \mathrm{C}$. The adrenals, thymus, heart, spleen and the muscles of the hind limb-extensor digitorum longus, tibialis anterior and soleus, and the parametrial, mesenteric and retroperitoneal adipose tissues were rapidly excised and weighed.

\section{Preparation of protein extracts}

The frozen hippocampus and hypothalamus from each animal were placed into an ultracentrifuge Eppendorf tube containing five volumes of ice-cold TEGMD buffer $(20 \mathrm{mmol} / \mathrm{l}$ Tris, $1 \mathrm{mmol} / \mathrm{l}$ EDTA, $10 \%$ glycerol, $10 \mathrm{mmol} / \mathrm{l}$ sodium molybdate, and $1 \mathrm{mmol} / \mathrm{l}$ dithiothreitol) with protease inhibitors. Tissue and cells were disrupted with a Soniprep 150 Ultrasonic disintegrator (MSE Sanyo Galtenkamp Plc, Loughborough, UK). Complete homogenization was confirmed by light microscopy. Following centrifugation at $2{ }^{\circ} \mathrm{C}$ for $45 \mathrm{~min}$ at $105000 \boldsymbol{g}$ (Optima TLX Ultracentrifuge, Beckman Coulter Inc., Palo Alto, CA, USA), the supernatant was collected, aliquoted and stored at $-80{ }^{\circ} \mathrm{C}$. Protein content was determined using the bicinchoninic acid protein assay (Pierce Chemical Co., Rockford, IL, USA).

\section{Western blot analysis of GR protein}

A sample from each individual $(20 \mu \mathrm{g}$ total protein from the hippocampus or the hypothalamus) was mixed with $4 \times$ sodium dodecyl sulfate (SDS) sample buffer, boiled for $5 \mathrm{~min}$ and resolved by electrophoresis in $8 \%$ SDS-PAGE gels in Tris-glycine-SDS buffer. Protein was electrophoretically transferred to polyvinylidene difluoride Western blotting membranes (Roche Molecular Biochemicals, Mannheim, Germany) in
Tris-glycine-methanol buffer (overnight at $4^{\circ} \mathrm{C}$, $200 \mathrm{~mA}$ ) using a Trans-Blot Electrophoresis Transfer Cell (Bio-Rad Laboratories, Inc., Hercules, CA, USA). The membranes were blocked for $1 \mathrm{~h}$ at room temperature with 5\% non-fat dry milk in Tris-buffered salineTween (TBS-T), washed briefly in TBS-T and incubated for $1 \mathrm{~h}$ at room temperature in TBS-T with $1 \%$ non-fat dry milk, containing the appropriate dilution of antibody (1:5000 monoclonal anti-actin (clone AC-40; Sigma Chemical Co.) and 1:2000 polyclonal anti-GR (M-20; Santa Cruz Biotechnology, Santa Cruz, CA, USA)). Membranes were washed in TBS-T and placed in TBS-T with 1\% non-fat dry milk containing a 1:2000 dilution of peroxidase-conjugated secondary anti-rabbit and anti-mouse antibody respectively (Amersham Life Science, Arlington Heights, IL, USA) for $1 \mathrm{~h}$ at room temperature. Blots were washed in TBS-T and visualized with Western blot Chemiluminescence Reagent Plus (NEN Life Science Products, Boston, MA, USA), exposed to ECL hyperfilm (Amersham Life Science) and quantified on the Fluor-S MultiImager using Quantity One software (Bio-Rad Laboratories).

\section{Analytical methods}

Blood was collected in heparinized microtubes and centrifuged immediately in a microcentrifuge. Plasma concentrations of glucose were enzymatically determined on a YSI 2700 SELECT biochemical analyzer (YSI Inc., Yellow Springs, OH, USA). Plasma insulin and leptin were analyzed by radioimmunoassay (Rat Insulin RIA kit and Rat Leptin RIA kit, Linco Research, St Charles, MO, USA). Progesterone and 17 $\beta$-estradiol were assayed with commercially available enzymelinked immunosorbent assays (progesterone ELISA and estradiol ELISA; Biomar Diagnostic Systems, Marburg, Germany). Testosterone was measured with a solidphase radioimmunoassay (Coat-A-Count Total Testosterone, Diagnostic Products, Los Angeles, CA, USA). A radioimmunoassay was used for corticosterone measurement (RSL ${ }^{125}$ I corticosterone RIA; ICN Biomedicals, Costa Mesa, CA, USA). Insulin collected during the clamp measurements was analyzed with a double antibody radioimmunoassay (Pharmacia, Uppsala, Sweden).

\section{Statistical analysis}

All results are presented as means \pm S.E.M. The statistical methods used were two-way analysis of variance (ANOVA) for the locomotion and stress tests and the unpaired Student's t-test for the remaining analyses. All analyses were undertaken using the StatView software in the Macintosh system (SAS Institute Inc. Cary, NC, USA). 


\section{Results}

\section{Pups}

Plasma corticosterone in pups decapitated $6 \mathrm{~h}$ after receiving the corticosterone injection were below detection levels.

\section{Body weight, food intake and body composition}

The body weight development at 4-10 weeks of age in CORT rats and control rats is shown in Fig. 1. From 6 weeks of age and onwards, CORT rats weighed significantly less than control rats $(P<0.05-0.001)$. Food intake was significantly lower in CORT-treated rats than in control rats at 9 weeks of age $(16.0 \pm 0.7 \mathrm{~g} /$ day in CORT rats, $n=3$ cages and 19.3 \pm $0.5 \mathrm{~g} /$ day in control rats, $n=3$ cages; $P<0.01$ ).

In Table 1 the total body weight and the tissue weight in 10-week-old female CORT rats and control rats are presented. The CORT rats weighed significantly less than did the control rats $(P<0.001)$. The parametrial $(P<0.05)$, retroperitoneal $(P<0.05)$, and mesenteric $(P<0.05)$ fat depots all weighed significantly less in CORT rats than in control rats. The muscle weights were not different between the groups. The CORT rats had an enlarged spleen and heart compared with control rats $(P<0.05)$, but there were no significant changes in the weights of the adrenals and thymus.

\section{Hormonal analyses}

The CORT group had a significantly lower fasting plasma concentration of leptin than did the control group $(0.47 \pm 0.06 \mathrm{ng} / \mathrm{ml}, \quad n=11$ and $0.82 \pm$

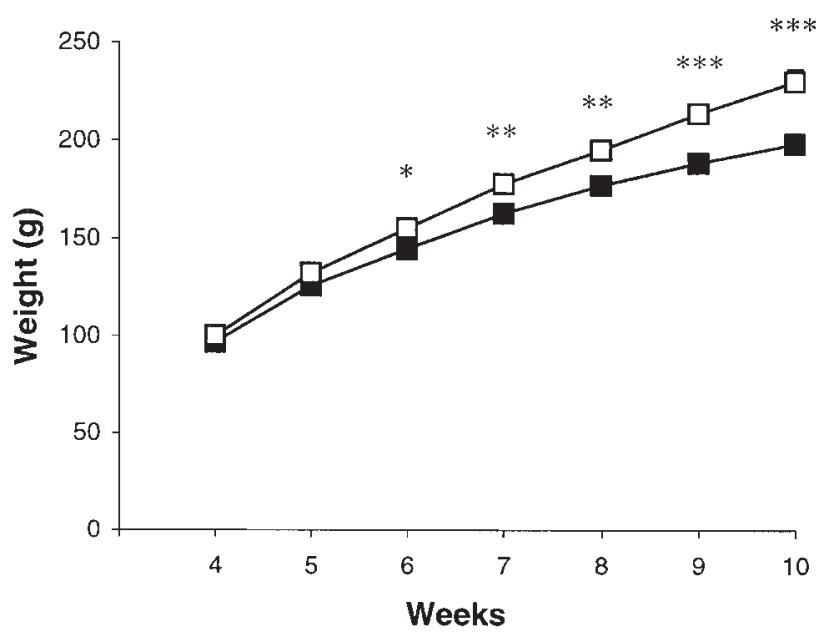

Figure 1 Development of total body weight $(\mathrm{g})$ from 4 weeks to 10 weeks of age in CORT-treated $(n=11 ; \boldsymbol{c})$ and control $(n=10 ; \square)$ rats. Data are presented as means \pm S.E.M.; ${ }^{\star} P<0.05,{ }^{* \star} P<0.01,{ }^{* * *} P<0.001$ (unpaired Student's $t$-test).
$0.06 \mathrm{ng} / \mathrm{ml}, n=10$; $P<0.001)$. CORT rats and control rats did not differ in fasting plasma concentrations of insulin $(6.6 \pm 0.8 \mathrm{mU} / \mathrm{l}, n=11$ and $8.0 \pm 1.2 \mathrm{mU} / \mathrm{l}$, $n=10)$, testosterone $(0.12 \pm 0.01 \mathrm{nmol} / \mathrm{l}, n=11$ and $0.10 \pm 0.01 \mathrm{nmol} / \mathrm{l}, \quad n=10), \quad 17 \beta$-estradiol $\quad(146 \pm$ $17 \mathrm{pmol} / \mathrm{l}, n=11$ and $135 \pm 20 \mathrm{pmol} / \mathrm{l}, n=10)$ and progesterone $(108 \pm 7 \mathrm{nmol} / \mathrm{l}, \quad n=11$ and $115 \pm$ $15 \mathrm{nmol} / \mathrm{l}, n=10)$.

\section{Locomotion test}

Figure 2 shows the locomotor activity in a novel environment (exploratory behavior) of 8-week-old rats from the CORT study. As usually observed when rats are placed in a new environment, the locomotor activity was initially high but declined markedly during the observation period (habituation). The ANOVA results showed that in both groups the exploratory locomotion was dependent on time $(P<0.001)$. There were, however, no significant differences in locomotor activity between treated rats and control rats.

\section{Basal and stress-induced corticosterone secretion}

Figure 3 shows plasma corticosterone levels in 5-weekold CORT rats and control rats after they were singly transferred to a new cage. The ANOVA repeated measures showed that there was a significant effect of treatment before and during stress exposure $(P<$ 0.05). When comparing the groups at individual time points with unpaired Student's t-test, CORT rats had lower corticosterone levels than did the control rats before exposure to $(P<0.01)$, and after 15 (short term effect) and 90 min (long term effect) in the new environment $(P<0.05)$. Table 2 shows the difference

Table 1 Total body weight $(\mathrm{g})$ and weights of extensor digitorum longus (EDL), soleus and tibialis anterior (TIB) muscles, parametrial, retroperitoneal and mesenteric adipose tissue, adrenals, thymus, spleen and heart ( $\mathrm{g} / \mathrm{kg} \mathrm{bw}$ ) in 10-week-old femal CORT-treated and control rats. Data are means \pm S.E.M.

\begin{tabular}{lcc}
\hline & Control $(n=10)$ & Corticosterone $(n=11)$ \\
\hline Total body wt $(\mathrm{g})$ & $230 \pm 6$ & $198 \pm 3^{* * *}$ \\
Skeletal muscle $(\mathrm{g} / \mathrm{kg}$ bw) & \\
EDL & $0.40 \pm 0.01$ & $0.39 \pm 0.02$ \\
Soleus & $0.38 \pm 0.01$ & $0.39 \pm 0.01$ \\
TIB & $1.93 \pm 0.04$ & $1.93 \pm 0.07$ \\
Adipose tissue (g/kg bw) & \\
Parametrial & $23.7 \pm 1.5$ & $18.1 \pm 1.7^{*}$ \\
Retroperitoneal & $16.4 \pm 1.0$ & $12.6 \pm 1.3^{*}$ \\
Mesenteric & $11.7 \pm 0.6$ & $9.8 \pm 0.4^{*}$ \\
Other tissue (g/kg bw) & & \\
Adrenals & $0.40 \pm 0.02$ & $0.40 \pm 0.01$ \\
Thymus & $2.42 \pm 0.15$ & $2.37 \pm 0.07$ \\
Spleen & $2.20 \pm 0.07$ & $2.52 \pm 0.11^{*}$ \\
Heart & $2.91 \pm 0.06$ & $3.14 \pm 0.09^{*}$ \\
\hline
\end{tabular}

bw, body weight.

${ }^{\star} P<0.05,{ }^{* * *} P<0.001$. 


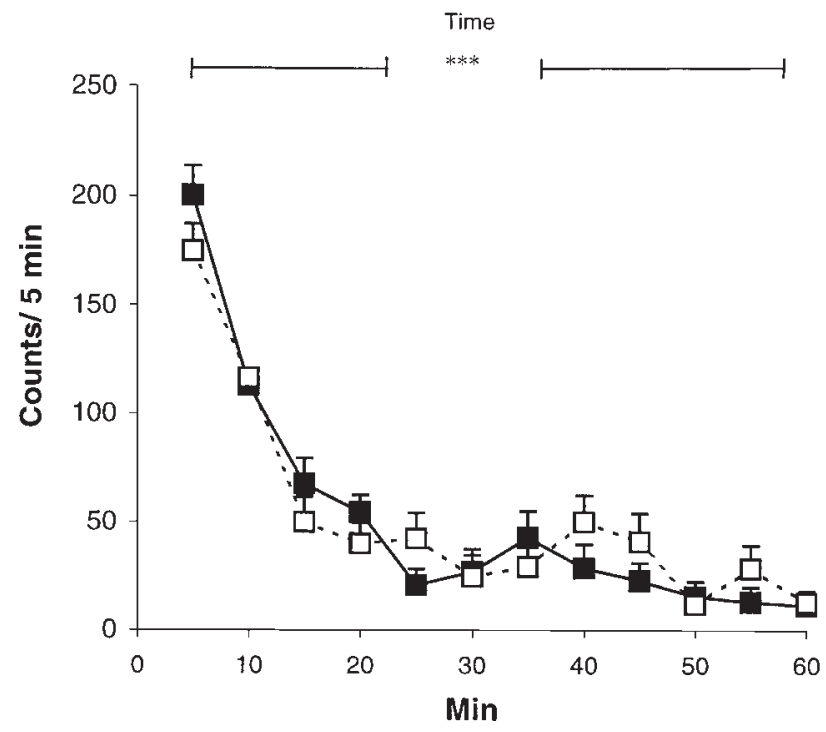

Figure 2 Locomotor activity (counts $/ 5 \mathrm{~min}$ ) in 8-week-old, CORTtreated $(n=10 ; \mathbf{\square})$ and control $(n=9 ; \square)$ rats. Data are presented as means \pm S.E.M.; ${ }^{* * *} P<0.001$ for time (two-way ANOVA).

between corticosterone response to stress at 15, 30, 60 and $90 \mathrm{~min}$ and basal levels. This shows that the amplitude of the corticosterone response after the stress exposure was similar between the two groups and no difference in stress response was seen between the groups at any point in time.

\section{Euglycemic hyperinsulinemic clamp (5 mU/kg/min)}

In Fig. 4, the glucose infusion rate during the euglycemic, hyperinsulinemic clamp in CORT-treated and control rats is shown. The CORT rats exhibited a significantly increased glucose infusion rate under steady state conditions, that is, at 60-200 min of clamp time $(20.2 \pm 1.5 \mathrm{mg} / \mathrm{kg} / \mathrm{min}$ for CORT rats, and $14.1 \pm 1.5 \mathrm{mg} / \mathrm{kg} / \mathrm{min}$ for controls; $P<0.05)$. There was no difference in plasma glucose levels $(6.8 \pm 0.05 \mathrm{mmol} / \mathrm{l}, n=10$ and $7.0 \pm 0.06 \mathrm{mmol} / \mathrm{l}, n=$ 9 in CORT-treated rats and controls respectively) during steady state $(60-200 \mathrm{~min})$, and there was no significant difference in mean plasma insulin levels between the groups $(90 \pm 6 \mathrm{mU} / \mathrm{l}, n=10$ and $101 \pm 7 \mathrm{mU} / \mathrm{l}, n=$ 9 in CORT-treated rats and controls respectively).

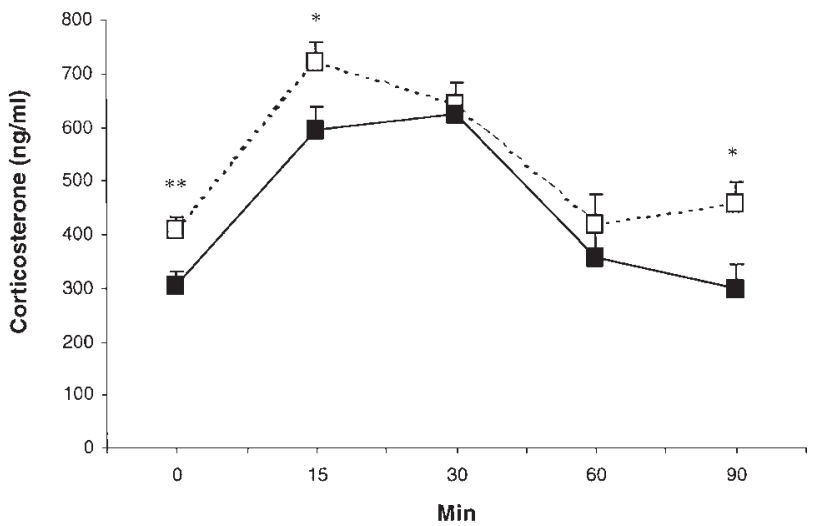

Figure 3 Plasma corticosterone levels in 5-week-old, CORTtreated $(n=11 ; \mathbf{\square})$ and control $(n=10 ; \square)$ female rats submitted to the novel environment stress test. Blood was sampled prior to and 15, 30, 60 and $90 \mathrm{~min}$ following stress exposure. Data are presented as means \pm S.E.M.; ${ }^{\star} P<0.05,{ }^{\star *} P<0.01$ (unpaired Student's $t$-test).

\section{Glucocorticoid receptor protein expression in the brain}

There were no differences in GR protein levels expressed as the GR:actin ratio, either in the hypothalamus (1.85 \pm 0.44 and $2.69 \pm 0.78$ for CORT rats, $n=8$, and controls, $n=8$, respectively) or in the hippocampus (1.33 \pm 0.18 in CORT rats, $n=10$ and $1.38 \pm$ 0.15 in controls, $n=9$ ).

\section{Discussion}

Low, constant levels of glucocorticoids are important to assure normal postnatal brain development in rats $(2$, 23). To secure low unperturbed glucocorticoid levels during the sensitive period, the first two postnatal weeks in rats are characterized by a stress-nonresponsiveness. This period, beginning on postnatal day 2 and continuing into postnatal week 2 , is referred to as the stress hyporesponsive period (SHRP). During this period, circulating corticosterone levels are low, and the HPA axis is relatively unresponsive to stimulatory effects of stress and to inhibitory effects of circulating glucocorticoids (6). Glucocorticoid exposure during this time has been shown to result in permanent effects on brain development $(8,9)$.

Table 2 Plasma corticosterone response to novel-environment stress test, expressed as the difference between plasma corticosterone at $15,30,60$ and 90 min and basal plasma corticosterone levels. Data are means \pm S.E.M.

\begin{tabular}{|c|c|c|c|c|c|}
\hline & $\begin{array}{l}\text { Basal } 0 \text { min } \\
(\mathrm{ng} / \mathrm{ml})\end{array}$ & $\begin{array}{c}15 \text { min-basal } \\
(\mathrm{ng} / \mathrm{ml})\end{array}$ & $\begin{array}{c}30 \underset{(\mathrm{mg} / \mathrm{ml} \text {-basal }}{ } \\
\text {. }\end{array}$ & $\begin{array}{c}60 \underset{(\mathrm{mg} / \mathrm{ml})}{ } \\
\text { min-basal }\end{array}$ & $\begin{array}{c}90 \underset{(\mathrm{mg} \text { m-basal }}{ } \\
\text { (ml) }\end{array}$ \\
\hline Control $(n=10)$ & $408.7 \pm 23.6$ & $313.4 \pm 49.8$ & $233.5 \pm 59.7$ & $27.9 \pm 66.0$ & $48.8 \pm 56.5$ \\
\hline CORT $(n=11)$ & $306.7 \pm 25.8^{* *}$ & $287.5 \pm 48.6$ & $318.6 \pm 38.1$ & $54.1 \pm 57.0$ & $-7.0 \pm 42.5$ \\
\hline
\end{tabular}

${ }^{\star \star} P<0.01$. 


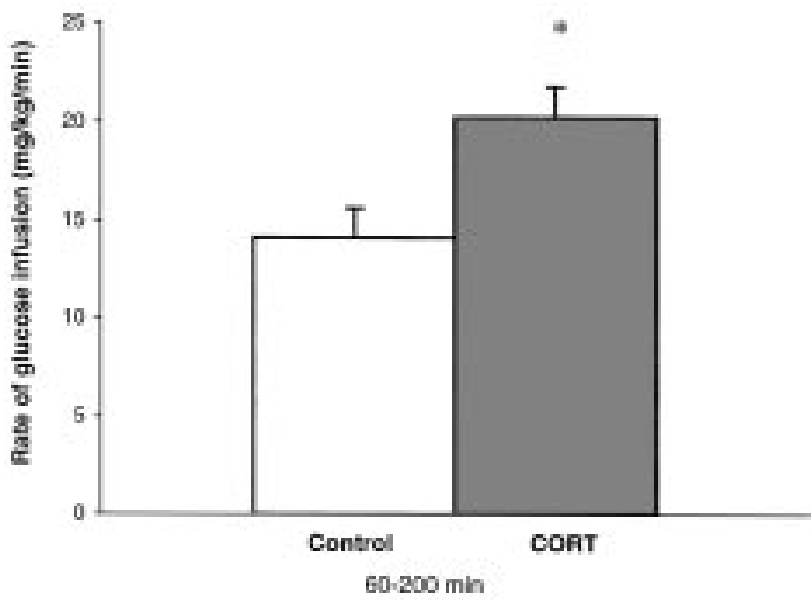

Figure 4 Glucose infusion rate at steady state $(60-200 \mathrm{~min})$ during the euglycemic hyperinsulinemic clamp $(5 \mathrm{mU} / \mathrm{kg} / \mathrm{min})$, performed on 10-week-old female, CORT-treated rats $(n=10$; solid bar) and control rats ( $n=9$; open bar). Plasma glucose concentrations were $\sim 6.8 \mathrm{mmol} / \mathrm{l}$ in both groups. Data are presented as means \pm S.E.M.; ${ }^{*} P<0.05$ (unpaired Student's $t$-test).

In a recent study from our laboratory, we observed that $6 \mathrm{~h}$ after exposure to endotoxin during SHRP, glucocorticoid levels were significantly increased and long term consequences on insulin sensitivity and HPA and hypothalamo-pituitary-gonadal (HPG) axes regulation in the adult female offspring were seen (15). The present study was performed to explore if some of the endotoxin effects were mediated by the glucocorticoid secretion peak. Corticosterone was injected into female pups on postnatal days 3 and 5 , at the beginning of the SHRP. The permanent effects on neuroendocrine function, body composition and insulin sensitivity were examined in the adult female rat. Postnatal corticosterone exposure was shown to result in lower basal HPA axis activity and lower circulating leptin levels. Furthermore, leanness, reduction in food intake and an increased sensitivity to insulin were seen in the adult animals.

The result of the novel environment stress test points to a programming effect on the HPA axis after postnatal corticosterone exposure. This is in accordance with previous studies showing that postnatal manipulations, such as maternal deprivation or handling lead to long lasting effects in HPA axis activity and programming of central GRs. However, it seems that different kinds of manipulations result in different responses in the adult offspring (13). In our study, CORT rats had lower non-fasting, pre-stress corticosterone levels, and also lower corticosterone levels at 15 and $90 \mathrm{~min}$ of stress exposure. When the difference between stress corticosterone levels and basal levels was considered, the corticosterone response to stress did not differ between the groups. It seems, therefore, that postnatal glucocorticoid exposure lowered the set-point of corticosterone secretion, at basal conditions and also under stress conditions. Felszeghy and co-workers reported a lower corticosterone response to restraint stress in adult rats treated neonatally with dexamethasone (12). This was not, however, as in our study, accompanied by lower basal corticosterone levels. Furthermore, they reported a reduction of GR binding capacity in hippocampus, hypothalamus and pituitary (12).

In the present study, no differences in GR protein levels were detected with Western blot, either in the hippocampus or in the hypothalamus. However, it cannot be excluded that postnatal glucocorticoid exposure led to changes in function of central GRs. It is also possible that the number and function of mineralocorticoid receptors (MR) were affected. MRs mediate several physiological actions of glucocorticoids during the early postnatal period and regulate basal glucocorticoid levels $(24,25)$.

Another possible explanation for the effects observed on HPA axis activity is that the postnatal corticosterone exposure caused neuronal damage in the parvocellular neurons, secreting corticotropin-releasing hormone $(\mathrm{CRH})$ and arginine vasopressin, which stimulate the pituitary adrenocorticotropin release in response to stress. The development and function of the parvocellular neurons are known to be influenced by glucocorticoids, postnatal handling or maternal deprivation during development $(14,26)$.

Postnatal CORT treatment resulted in leanness, probably due to reduced food intake. Low body weight at adult age after postnatal glucocorticoid treatment has been reported previously (17). This may be the result of the low basal corticosterone levels seen in this group, since food intake is known to be affected by glucocorticoids (27). Plasma leptin levels strongly correlate with adipose tissue mass, thus the low leptin levels are probably a consequence of the decrease in adipose tissue mass (28). Weight loss and a decrease in leptin levels normally signal nutrient deprivation and lead to an increase in food intake through hypothalamic receptors involved in energy intake regulation (29). Despite low leptin levels, CORT rats had a decreased food intake as compared with controls, indicating improper functioning of the regulation of food intake and energy expenditure. The systems regulating the HPA axis and leptin secretion are interconnected, with leptin stimulating the secretion of $\mathrm{CRH}$ from the hypothalamus under basal conditions and inhibiting the HPA axis in response to stress $(30,31)$. On the other hand, glucocorticoids stimulate the synthesis and secretion of leptin and have also been suggested to have an inhibitory effect on leptin sensitivity $(32,33)$. The results of this study may be a consequence of a disruption of the central CRH and/or leptin system regulating food intake and energy expenditure.

Postnatal corticosterone exposure results in increased insulin sensitivity in adult female rats. Prenatal dexamethasone exposure has been shown to result in both basal and reactive hyperglycemia, 
whereas postnatal dexamethasone did not affect basal glucose levels or response to an oral glucose load (34). The increased insulin sensitivity seen in postnatally corticosterone-exposed rats is probably a consequence of the leanness in these rats. However, it may also be a direct effect of low circulating corticosterone levels, since glucocorticoids are known to exert anti-insulin effects (35). Although, in this study, exploratory behavior was not affected by postnatal exposure to corticosterone, previous studies have shown that postnatal glucocorticoid exposure leads to long-term increased general motor activity and novelty-induced ambulation (2). Exercise is known to increase sensitivity to insulin (36). Even if exploratory behavior was not affected in this study, an effect on general motor activity cannot be excluded, leading to the increased insulin sensitivity seen after postnatal corticosterone exposure.

To summarize, the effects seen on body composition, food intake and insulin sensitivity in this study may be the result of low circulating glucocorticoid levels. The direct influence of corticosterone may have changed the basal HPA axis regulation (37). The level of this damage cannot be determined, but it did not seem to have affected GR density in the hippocampus or hypothalamus, exerting feedback regulation of the HPA axis activity. Glucocorticoids are involved in food intake regulation (27), and therefore, a decreased food intake, as well as diminished body weight, fat depots, and leptin, and increased insulin sensitivity, may well be consequences of the relative corticosterone deficiency in this group. Increased insulin sensitivity was also seen after postnatal endotoxin exposure, but the effects on HPA axis regulation in the two studies are disparate (15). The results from the present study suggest that part of the effects of postnatal endotoxin exposure on insulin sensitivity may be mediated by glucocorticoids. However, glucocorticoid exposure experienced after endotoxin treatment is most likely qualitatively and quantitatively different from the one in this study.

Recent research suggests that a person's experience in very early life, programming, may be an important determinant of the risk of contracting several major diseases in later life including cardiovascular disease, hypertension, stroke, obesity and type 2 diabetes. One of the possible mechanisms involved is programming of the HPA axis. The present work demonstrates that postnatal exposure to corticosterone during a period of extensive brain development is followed by changed HPA axis activity, leanness and increased sensitivity to insulin in female pups. To further elucidate the mechanisms involved, additional studies will be required.

\section{Acknowledgements}

The laboratory assistance of Britt-Mari Larsson and Inger Oscarsson is gratefully acknowledged.
This study was supported by grants from the Swedish Medical Research Council (project no. 12206, no. 8668), the Knut and Alice Wallenberg Foundation, Astra Arcus, the Magnus Bergwall Foundation, The Novo Nordisk Foundation and the Swedish Heart and Lung Foundation.

\section{References}

1 NIH Consensus Development Panel. Effect of corticosteroids for fetal maturation on perinatal outcomes. NIH consensus development panel on the effect of corticosteroids for fetal maturation on perinatal outcomes. Journal of the American Medical Association $1995273413-418$.

2 De Kloet ER, Rosenfeld P, Van Eekelen JA, Sutanto W \& Levine S. Stress, glucocorticoids and development. Progress in Brain Research 198873 101-120.

3 Dahlgren J, Nilsson C, Jennische E, Ho H-P, Eriksson E, Niklasson A et al. Prenatal cytokine exposure results in obesity, and genderspecific programming of neuroendocrine axes in adult rats. American Journal of Physiology 2001281 326-334.

4 Levitt NS, Lindsay RS, Holmes MC \& Seckl JR. Dexamethasone in the last week of pregnancy attenuates hippocampal glucocorticoid receptor gene expression and elevates blood pressure in the adult offspring in the rat. Neuroendocrinology $1996 \mathbf{6 4}$ $412-418$.

5 Nyirenda MJ, Lindsay RS, Kenyon CJ, Burchell A \& Seckl JR. Glucocorticoid exposure in late gestation permanently programs rat hepatic phosphoenolpyruvate carboxykinase and glucocorticoid receptor expression and causes glucose intolerance in adult offspring. Journal of Clinical Investigation $19981012174-2181$.

6 Sapolsky RM \& Meaney MJ. Maturation of the adrenocortical stress response: neuroendocrine control mechanisms and the stress hyporesponsive period. Brain Research 1986396 64-76.

7 Dobbing J \& Sands J. Quantitative growth and development of human brain. Archives of Diseases in Childhood $1973 \mathbf{4 8}$ $757-767$.

8 Ardeleanu A \& Sterescu N. RNA and DNA synthesis in developing rat brain: hormonal influences. Psychoneuroendocrinology 19783 93-101.

9 Balazs R \& Cotterrell M. Effect of hormonal state on cell number and functional maturation of the brain. Nature 1972236 $348-350$.

10 Olton DS, Johnson CT \& Howard E. Impairment of conditioned active avoidance in adult rats given corticosterone in infancy. Developmental Psychobiology 1974 8 55-61.

11 Meaney MJ, Stewart J \& Beatty WW. The influence of glucocorticoids during the neonatal period on the development of play-fighting in Norway rat pups. Hormones and Behavior 1982 16 475-491.

12 Felszeghy K, Bagdy G \& Nyakas C. Blunted pituitary-adrenocortical stress response in adult rats following neonatal dexamethasone treatment. Journal of Neuroendocrinology 200012 1014-1021.

13 Meaney MJ, Diorio J, Francis D, Widdowson J, LaPlante P, Caldji C et al. Early environmental regulation of forebrain glucocorticoid receptor gene expression: implications for adrenocortical responses to stress. Developmental Neuroscience 199618 49-72.

14 Plotsky PM \& Meaney MJ. Early, postnatal experience alters hypothalamic corticotropin-releasing factor (CRF) mRNA, median eminence CRF content and stress-induced release in adult rats. Brain Research. Molecular Brain Research 199318 195-200.

15 Nilsson C, Jennische E, Ho H-P, Eriksson E, Bjorntorp P \& Holmang A. Postnatal endotoxin exposure results in increased insulin sensitivity and altered activity of neuroendocrine axes in adult female rats. European Journal of Endocrinology 2002146 $251-260$. 
16 Witek-Janusek L. Pituitary-adrenal response to bacterial endotoxin in developing rats. American Journal of Physiology 1988 255 E525-E530.

17 Taylor MH \& Howard E. Impaired glucose homeostasis in adult rats after corticosterone treatment in infancy. Endocrinology 197188 1190-1202.

18 Raju VS, McCoubrey WK Jr \& Maines MD. Regulation of heme oxygenase- 2 by glucocorticoids in neonatal rat brain: characterization of a functional glucocorticoid response element. Biochimica et Biophysica Acta $1997135189-104$.

19 Smith MS, Freeman ME \& Neill JD. The control of progesterone secretion during the estrous cycle and early pseudopregnancy in the rat: prolactin, gonadotropin and steroid levels associated with rescue of the corpus luteum of pseudopregnancy. Endocrinology $197596219-226$.

20 Ericson E, Samuelsson J \& Ahlenius S. Photocell measurements of rat motor activity. A contribution to sensitivity and variation in behavioral observations. Journal of Pharmacological Methods $199125111-122$.

21 Lahti RA \& Barsuhn C. The effect of minor tranquilizers on stressinduced increases in rat plasma corticosteroids. Psychopharmacologia $197435215-220$.

22 Holmang A, Svedberg J, Jennische E \& Bjorntorp P. Effects of testosterone on muscle insulin sensitivity and morphology in female rats [published erratum appears in American Journal of Physiology 1993264 section E]. American Journal of Physiology 1990259 E555-E560.

23 Bohn M. Glucocorticoid induced teratologies of the nervous system. In Neurobehavioral Teratology, pp 365-387. Ed. J Yanai New York: Elsevier Science Publisher, 1984.

24 Rosenfeld P, van Eekelen JA, Levine S \& de Kloet ER. Ontogeny of corticosteroid receptors in the brain. Cellular and Molecular Neurobiology 199313 295-319.

25 Ratka A, Sutanto W, Bloemers M \& de Kloet ER. On the role of brain mineralocorticoid (type I) and glucocorticoid (type II) receptors in neuroendocrine regulation. Neuroendocrinology $1989 \mathbf{5 0}$ $117-123$.

26 Unno N, Wu WX, Ding XY, Li C, Hing WK \& Nathanielsz PW. The effects of fetal adrenalectomy at 110 days gestational age on AVP and CRH mRNA expression in the hypothalamic paraventricular nucleus of the ovine fetus. Brain Research. Developmental Brain Research 1998106 119-128.

27 Jacobson L. Glucocorticoid replacement, but not corticotropinreleasing hormone deficiency, prevents adrenalectomy-induced anorexia in mice. Endocrinology 1999140 310-317.
28 Maffei M, Halaas J, Ravussin E, Pratley RE, Lee GH, Zhang Y et al. Leptin levels in human and rodent: measurement of plasma leptin and ob RNA in obese and weight-reduced subjects. Nature Medicine 19951 1155-1161.

29 Rohner-Jeanrenaud E \& Jeanrenaud B. Central nervous system and body weight regulation. Annals d'Endocrinologie $1997 \mathbf{5 8}$ 137-142.

30 Costa A, Poma A, Martignoni E, Nappi G, Ur E \& Grossman A. Stimulation of corticotrophin-releasing hormone release by the obese (ob) gene product, leptin, from hypothalamic explants. Neuroreport 19978 1131-1134.

31 Heiman ML, Ahima RS, Craft LS, Schoner B, Stephens TW \& Flier JS. Leptin inhibition of the hypothalamic-pituitary-adrenal axis in response to stress. Endocrinology 1997138 3859-3863.

32 Zakrzewska KE, Cusin I, Sainsbury A, Rohner-Jeanrenaud F \& Jeanrenaud B. Glucocorticoids as counterregulatory hormones of leptin: toward an understanding of leptin resistance. Diabetes 199746 717-719.

33 Slieker LJ, Sloop KW, Surface PL, Kriauciunas A, LaQuier F, Manetta J et al. Regulation of expression of ob mRNA and protein by glucocorticoids and cAMP. Journal of Biological Chemistry 1996 271 5301-5304.

34 Nyirenda MJ, Welberg LA \& Seckl JR. Programming hyperglycaemia in the rat through prenatal exposure to glucocorticoids fetal effect or maternal influence? Journal of Endocrinology 2001 170 653-660.

35 Chavez M, Seeley RJ, Green PK, Wilkinson CW, Schwartz MW \& Woods SC. Adrenalectomy increases sensitivity to central insulin. Physiology and Behavior 199762 631-634.

36 Richter EA, Garetto LP, Goodman MN \& Ruderman NB. Muscle glucose metabolism following exercise in the rat: increased sensitivity to insulin. Journal of Clinical Investigation 198269 $785-793$.

37 Blanchard DC, Spencer RL, Weiss SM, Blanchard RJ, McEwen B \& Sakai RR. Visible burrow system as a model of chronic social stress: behavioral and neuroendocrine correlates. Psychoneuroendocrinology $199520117-134$.

Received 19 October 2001

Accepted 21 March 2002 